\title{
Artigo
}

\section{Entre a mudança e a resiliência: o papel do dólar no período pós crise de 2008}

Between Change And Resilience: The Role Of The Dollar In The Post-2008 Crisis Period

Tom Claudino dos Santos ${ }^{3}$

DOI: $10.5752 / \mathrm{P} .1809-6182.2018 \mathrm{v} 15 . \mathrm{n} 2 . \mathrm{p} 22$

\section{Resumo}

O presente artigo tem como objetivo explorar as razóes pelas quais o dólar manteve sua posição dominante no sistema monetário e financeiro internacional no periodo pós-2008. Argumenta-se que a base de sustentação do dólar foi o setor financeiro estadunidense, notadamente o mercado de títulos da divida dos EUA.

Palavras chave: dólar; financeirização; hierarquia monetária

\section{Abstract}

The purpose of this paper is to explore the reasons why the dollar maintained its dominance in the international monetary and financial system in the post-2008 period. It is argued that the base of support for the dollar has been the financial sector, mainly the market for US treasury bonds.

Key words: Dollar, Financialization; Monetary Hierarchy

3. Professor de economia da Uniavan. Mestrando em Relações Internacionais na Universidade Federal de Santa Catarina (UFSC) e mestre em economia pela Université Paris XIII. ORCID: 0000-0003-2680-6697 


\section{INTRODUÇÃO}

A despeito das previsóes de que o dólar enfrentava sua crise derradeira após a crise de $2008^{4}$, a moeda estadunidense ainda é a divisa central do sistema monetário internacional. As previsóes de que o dólar perderia sua relevância datam desde os anos $1960 \mathrm{e}$ 1970, quando acadêmicos como Triffin (1960) e Bergsten (1976) já identificavam uma série de fragilidades no padrão dólar-ouro e previam uma diminuição do status do dólar como moeda internacional. Nos anos 1980, outros autores como Keohane (2005) e Gilpin (1981) argumentavam que, em termos mais gerais, a liderança global exercida pelos EUA estava em declínio e que o papel do dólar estava ameaçado. Após a quebra do banco Lehman Brothers e da crise financeira global de 2008, novamente uma gama de autores apontavam para a possibilidade de mudanças estruturais no sistema financeiro e monetário internacional (SFMI) 5 .

No entanto, mesmo após os abalos sistêmicos que a crise provocou na economia global e 10 anos passados da mesma, não existem evidências que o dólar tenha se enfraquecido. Como será abordado em maior profundidade nas sessóes seguintes, para determinados usos, o dólar inclusive ganhou maior relevância. Neste sentido, cabe questionar quais os mecanismos que justificam a contínua dominação do padrão monetário centrado no dólar. Com o intuito de responder a este questionamento, o presente artigo explora quais são os condicionantes da manutenção do regime centrado no dólar e como a moeda manteve tamanha importância mesmo dez anos após a deflagração da crise subprime. $\mathrm{Na}$ primeira parte do artigo, desenha-se brevemente a teoria de Economia Política Internacional em rela-

4. Para uma descrição detalhada da crise subprime, ver Guttmann (2016, cap.1).

5. Ver Helleiner e Kirshner (2009), onde as perspectivas de diversos autores dentro do livro convergem no entendimento de que o futuro do dólar estava ameaçado. ção aos condicionantes econômicos da internacionalização monetária. Em seguida, dados relativos à utilização do dólar para seus diversos papeis são discutidos, o que fornece sólidas evidências que a moeda estadunidense continua a ocupar o topo da hierarquia monetária internacional. Por fim, algumas considerações finais são traçadas.

\section{Teoria da internacionalização monetória}

Esta sessão tem como objetivo delinear quais os papeis que uma moeda internacional desempenha e quais são os condicionantes econômicos para a internacionalização monetária a partir de uma perspectiva de Economia Política Internacional. De acordo com Cohen (1998), a moeda desempenha três funçóes - meio de troca, unidade de conta e reserva de valor - em dois níveis de análise no âmbito internacional, o privado e o oficial (COHEN, 2015). A função de meio de troca da moeda se relaciona à sua capacidade de ser intermediária entre a troca de bens e serviços. O papel de unidade de conta se refere ao papel que a moeda desempenha como referencial de valor e instrumento pelo qual as mercadorias são cotadas. Por fim, o papel de reserva de valor concerne o fato de que a moeda pode ser um instrumento de entesouramento, mantendo assim o poder de compra através do tempo.

De modo mais específico, no âmbito privado, seguindo a divisáo de Cohen (2015), a moeda se configura como meio de troca nos mercados cambiais globais, nos quais atualmente são transacionados, numa base líquida, U\$ 5,06 trilhôes de dólares diariamente (BIS, 2018). Krugman (1984) chama este papel da "moeda de veicular". Esta função é similar de unidade de conta no âmbito privado. Quando diferentes agentes vão transacionar bens e serviços internacionalmente, ambas as partes precisam achar 
um denominador monetário para denominaçáo dos contratos, para a liquidação das transaçôes e efetuação dos pagamentos. Finalmente, a moeda desempenha sua função de reserva de valor, no âmbito privado, principalmente através dos mercados financeiros globais. É neles que os diversos atores buscam instrumentos para garantir a manutenção intertemporal do valor da moeda, onde diversos instrumentos permitem oportunidades de investimento, de financiamento, gerenciamento do risco e especulação financeira (KRUGMAN, 1984).

No âmbito oficial -na utilização da moeda por agentes públicos - a funçáo de unidade de conta se expressa como âncora cambial, na qual as autoridades monetárias compram ou vendem divisas internacionais para manter o câmbio em um nível desejado, atrelado à uma moeda de referência. Já a função de meio de troca no âmbito oficial se traduz na moeda de intervenção das autoridades monetárias nos mercados cambiais. Por fim, quando um banco central acumula reservas como mecanismo de proteção contra fluxos de capitais voláteis ou como estratégia de manipulação do câmbio, ele utiliza a moeda como reserva de valor (COHEN, 2015).

Estas definiçôes são importantes pois elas permitem uma análise da moeda internacional não como uma entidade única, mas sim como um elemento que está em constante evolução, desempenhando diferentes papeis em distintos locais e períodos. No entanto, nota-se que há uma tendência significativa de complementariedade entre estes diferentes papeis. De acordo com De Conti, Prates e Plihon (2013, p.28), "Embora a definição das três funçôes da moeda seja importante do ponto de vista analítico, estas funçôes são completamente imbricadas".

Dadas estas premissas, cabe questionar o que, dentro do arcabouço teórico proposto, torna as moedas competitivas ao ponto de agentes públicos e privados quererem demandá-la. De acordo com Cohen (2015), existem fundamentalmente três as- pectos econômicos que conferem à moeda internacional competitividade: estabilidade de preços (baixa inflação), mercados financeiros desenvolvidos e uma grande rede transacional. Eicheengren (2011) tece uma definição similar, elencando como fatores essenciais para a internacionalizaçáo de uma moeda a estabilidade, a liquidez e a escala. Em uma revisão sobre o tema, Helleiner (2008, p.359) chega a uma conclusão semelhante: “[...] confiança, liquidez e redes transacionais são os determinantes econômicos chave de moedas internacionais"6.

Neste contexto, cabe especificar cada uma destas precondiçóes. Primeiramente, para que haja ampla confiança no valor futuro da moeda, é importante que a moeda apresente um nível de preços relativamente estável, sem um histórico de alta inflação ou ampla variabilidade da mesma. Do ponto de vista dos agentes econômicos, um nível de preços galopante mina a capacidade da moeda de desempenhar suas funçóes tradicionais, principalmente como reserva de valor (COHEN, 1998, 2015). Nas palavras de Mundell (2000, p.61), "Nenhuma moeda jamais sobreviveu como moeda internacional com uma alta taxa de inflação"”.

Em segundo lugar, a partir da perspectiva de Cohen (2015), é central que o país que emita a divisa internacional tenha mercados financeiros profundos e líquidos que garantam convertibilidade plena e segurança do valor dos ativos transacionados. Para Cohen (2015, p.11), os mercados financeiros devem apresentar "[...] profundidade, amplitude e resiliência" ${ }^{\prime}$. Por fim, uma terceira condiçăo econômica para internacionalização de uma moeda é o tamanho da economia emissora, ou o que Cohen $(1998,2015)$ denomina como uma ampla rede transacional. A

6. [tradução nossa] '[...] confidence, liquidity and transactional networks are the key economic determinants of international currencies'.

7. [Tradução nossa] "No currency has ever survived as an international currency with a high rate of inflation".

8. [tradução nossa] "depth, breadth, and resiliency". 
partir desta perspectiva, é fundamental que um país que tenha uma moeda internacional possua uma economia grande em tamanho absoluto e com significativa rede de relaçôes comerciais e financeiras, criando assim a demanda pela sua moeda. Nas palavras de Chinn e Frenkel (2005, p.298), "A moeda de um país que tem uma ampla participação na produção internacional, no comércio e nas finanças tem uma grande vantagem natural".?

Em linhas gerais, estas são as bases teóricas que justificariam o papel de uma moeda internacional a partir de uma dimensão econômica. Há ampla discussão sobre como estes elementos dialogam com os aspectos políticos da determinação de moedas internacionais, principalmente como capacidades militares e políticas se convertem em influência monetária (ex: NORLOFF, 2014). No entanto, apesar da importância desta discussão, o presente artigo não pretende abordar estes aspectos dado o limite de espaço. Pretende-se principalmente focar nos aspectos econômicos e como eles se relacionam com a demanda por diferentes moedas internacionais. Neste sentido, a próxima sessão busca complementar a visão tradicional dentro das EPI sobre os determinantes econômicos da internacionalização monetária com o intuito de compreender a resiliência do dólar na última década.

\section{A resiliência do dóla̛r no período pós 2008}

Uma primeira apreciação da divisão dos papeis de uma moeda internacional demonstra que, analiticamente, tal separação é fundamental para compreensão das principais características do sistema monetário internacional. No entanto, as três condiçôes para internacionali-

9. [tradução nossa] "The currency of a country that has a large share in international output, trade, and finance has a big natural advantage." zação monetária acabam por não conseguir dar a ênfase necessária ao setor financeiro e como este último é importante para a manutenção do padrão dólar. Ou seja, tem-se implícito que caso um país detenha as três características confiança, liquidez e redes transacionais - sua moeda passa a ser mais atrativa. Por mais que tal perspectiva aponte para a direção correta, é também importante considerar o lado da demanda, isto é, como o dólar desempenha funçôes específicas para os diversos agentes que decidem demandá-lo.

Neste sentido, parte-se da premissa que o atual regime de acumulaçáo ${ }^{10}$, o qual molda a demanda de diferentes agentes por moedas internacionais, pode ser caracterizado como um regime ${ }^{11}$ guiado pela financeirização, entendida em linhas gerais como "[...] a crescente importância dos mercados financeiros, motivos financeiros, instituiçôes financeiras e elites financeiras na economia e nas suas instituiçôes, tanto no nível nacional quanto internacional" (EPSTEIN, 2005, p.3).

Do ponto de vista da estrutura do sistema monetário internacional e do papel do dólar, esta transição para um regime financeirizado é importante pois a demanda por dólares dos diversos agentes, tanto público como privados, mudou conforme a demanda por ativos financeiros foi modificada. Em um regime financeirizado, não são mais as famílias os principais comprados de títulos públicos e privados, mas fundos e investidores institucionais (GUTTMANN, 2016). Neste contexto, os títulos denominados em dólar passam a ser vistos não só como dívida em si, mas principalmente como

10. Utiliza-se o termo no sentido daquele empregado pela Teoria da Regulaçáo. Para mais detalhes, ver Boyer (2000) e Guttmann (2016).

11. Para uma revisão do conceito e aprofundamento do tema, ver Guttamann (2016). 
instrumentos que permitem aos administradores de tais fundos cobrir os lapsos intertemporais entre entradas e saídas de capital, além de serem instrumentos que funcionam como reserva de valor em momentos de incerteza e garantem alta liquidez que permite o equilíbrio constante entre passivos e ativos. Por consequência, para que os títulos detenham a capacidade de desempenhar esses papeis, é importante a existência de um leque diversificado dos mesmos com múltiplos vencimentos, além de serviços auxiliares e ampla transparência, características amplamente disponíveis nos mercados estadunidenses (KALTENBRUNNER E LYSANDROU, 2017).

Ou seja, frente à um contexto de aumento da demanda por títulos como instrumentos que conferem liquidez e segurança, os EUA se encontram significativamente bem posicionados para satisfazer a demanda por tais instrumentos. Este argumento também é valido do ponto de vista das características da demanda autoridades monetárias de bancos centrais ao redor do globo que acumularam reservas em moedas estrangeiras. Desde o fim dos anos 1990, houve uma significativa expansão das reservas internacionais, principalmente por parte de países emergentes e em desenvolvimento, que objetivavam criar uma proteção contra fugas e ataques especulativos a suas moedas. Estas reservas são predominantemente denominadas em títulos do tesouro estadunidense, os quais não só permitem ampla liquidez, mas também a segurança de que em momentos de incerteza não ocorreram amplas variaçôes de preço dado a profundidade e amplitude do mercado de Treasuries (PRASAD, 2014). Por consequência, como é possível constatar no gráfico 1 , desde 2008 a participação do dólar como moeda de denominação de reservas internacionais alocadas se manteve constante em torno de 60\%.

Quando se parte da premissa de que os títulos emitidos nos EUA não sáo encarados pelo lado da demanda como dívida, mas principalmente como instrumentos de alta liquidez e segurança, é possível argumentar que não há um limite evidente para a acumulação da dívida estadunidense. Isto é, um argumento recorrente em torno da capacidade do dólar de manter seu status de moeda internacional é que a acumulação de estoques da dívida demasiadamente elevados comprometeriam a confiança dos investidores estrangeiros na moeda (ex: COHEN, 2015). No entanto, desde a quebra do padrão dólar-ouro em 1971, o dólar não tem mais qualquer limite evidente do ponto de vista da relação com

\section{Gráfico 1. Denominação das Reservas Internacionais Alocadas (\%) 2008-2017}

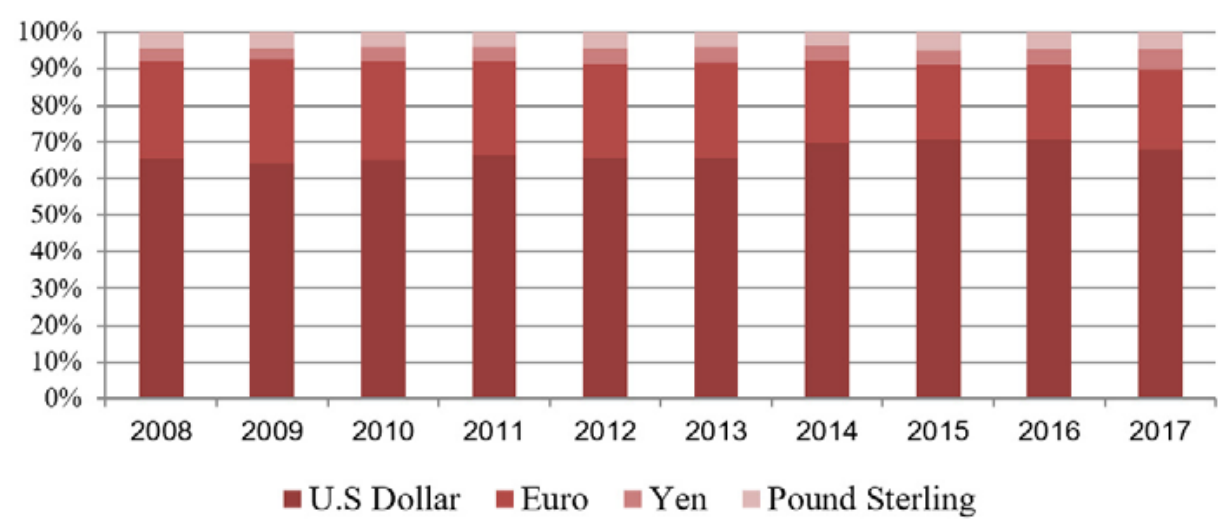

Fonte: FMI (2018). 
uma base metálica. Na prática, o dólar passa a ser demandado não porque ele possui lastro e pode ser convertido em uma determinada quantia de ouro, mas porque ele confere liquidez para os mercados, é a unidade de conta da riqueza financeira e oferece segurança para investidores em momentos de incerteza através dos títulos do tesouro (TAVARES, MELIN, 1997; TAVARES, 1985).

É possível constatar tal fato através de uma breve análise da estrutura dos mercados de títulos públicos estadunidenses e como, desde 2008, não houve uma mudança significativa em termos de demanda pelos mesmos. Neste mesmo ano, o estoque de títulos da dívida dos Estados Unidos somava U\$10,699.8 bilhões, sendo que 28,8\% deste estoque era de propriedade de investidores internacionais. É relevante notar que em dezembro de 2011 a agência de rating Standard and Poor's chegou a rebaixar a nota dos títulos do tesouro, mas nem isto afetou a demanda perene de atores internacionais: em dezembro de 2017, o estoque de títulos havia quase dobrado para U\$U \$20,492.7 bilhóes, dos quais $30,7 \%$ eram de propriedade de investidores estrangeiros (BUREAU OF FISCAL SERVICE, 2018). Portanto, percebe-se que não houve qualquer mudança significava na demanda internacional por títulos da dívida estadunidense, os quais continuaram a desempenhar seu papel como fonte de segurança e liquidez básica do SMFI.

Em termos de propriedade dos títulos do tesouro americano, como apontado no gráfico 2, é interessante notar que a China é atualmente a maior detentora dos mesmos, com $19 \%$ do total do estoque de títulos, com Japão em segundo (17\%) e a Irlanda em terceiro (5\%). Dentre os 10 países que mais possuem títulos, uma parte deles de fato detém reservas internacionais elevadas, como China (U\$3,2 trilhôes), Japão (U\$1,2 trilhões), Arábia Saudita (U\$547,2 bilhôes) e Brasil (U\$373, 9 bilhões).
Gráfico 2. Propriedade dos Títulos do Tesouro (\%) - Maio de 2018

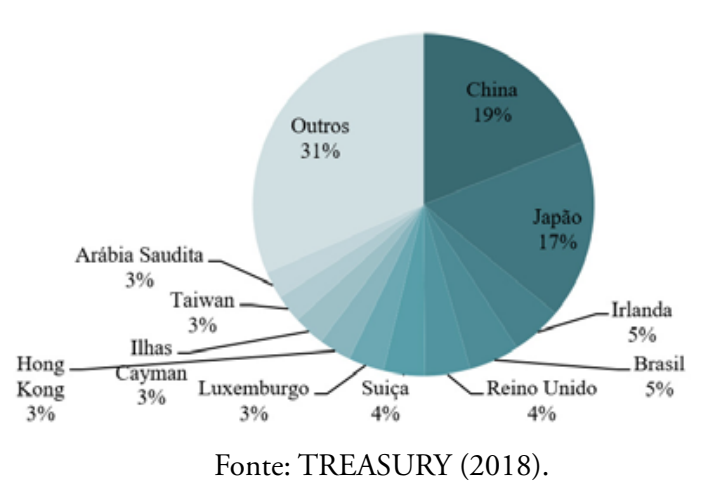

Do ponto de vista dos detentores dos títulos estadunidenses, pode-se afirmar que sua escolha não se dá tanto por opção mas por necessidade. Para a China, por exemplo, deter uma quantidade tâo elevada de títulos carrega uma série de dificuldades, tanto porque a remuneração destes tende a ser baixa e, frequentemente, negativa, o que implica uma perda real associada à um custo de oportunidade de investir em ativos com retornos mais atraentes, e também porque a flutuação na taxa de câmbio do dólar impacta diretamente nos preços dos títulos (PRASAD, 2016). De acordo com Helleiner (2014), por exemplo, a cada desvalorização de $10 \%$ do dólar, a China perdia aproximadamente 3\% do seu PIB somente em decorrência da desvalorizaçáo de seus ativos em dólar.

Em partes, tal dependência do mercado de títulos públicos estadunidenses se explica por uma falta de alternativas. Títulos europeus não gozam da mesma estabilidade e confiança em decorrência das diversas assimetrias entre países que constituem a zona do euro, além de questôes mais pontuais como as fragilidades do sistema bancário italiano e da questáo do endividamento da periferia europeia. A própria China abriu e expandiu seus mercados de títulos, tanto onshore quanto offshore, mas ainda existem sérias dúvidas de que os mercados chineses possam desempenhar o papel de safe haven em momentos de incerteza (HAGER, 2017). 


\section{Gráfico 3. Crédito total em dólares para tomadores não bancários em países emergentes - Bilhões de U\$ (2000-2017)}

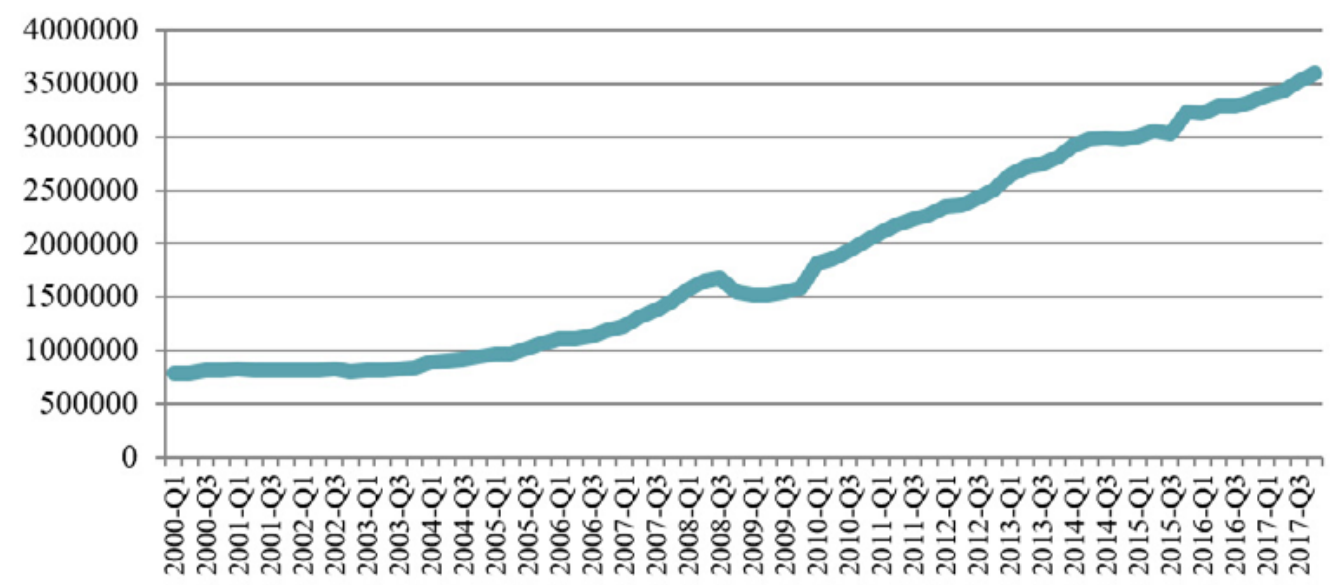

Fonte: BIS (2018) ${ }^{12}$.

A dependência do mercado financeiro dos EUA não se limita ao setor público de outros países. Frente as condições favoráveis de endividamento que marcaram o pós-2008, com baixos juros e ampla liquidez, o setor não financeiro de países emergentes e em desenvolvimento se endividou exponencialmente em dólares através da emissão de títulos da dívida corporativos, debentures e crédito bancário.

Como demonstrado no gráfico 3, os países emergentes passaram a se endividar em dólares num ritmo notadamente acelerado após 2008, acumulando um estoque de empréstimos na ordem de U\$3,59 trilhões de dólares no fim de 2017. De maneira mais específica, outro dado que corrobora a importância da moeda estadunidense é a utilização do dólar para a emissão de títulos da dívida internacionais. Neste sentido, em termos da denominação de títulos da dívida internacionais - emitidos fora da jurisdição aonde o emissor reside - o dólar ganhou espaço (gráfico 4), representando atualmente $44,5 \%$ das emissóes, porcentagem 10,6\% maior se comparada ao ano de 2012 (BIS, 2018).

12. Este indicador compreende a soma dos empréstimos bancários e a emissão de títulos da dívida para agentes não-bancários. Para mais detalhes sobre os dados, ver BIS (2018).
Outra evolução importante que denota a contínua importância do dólar foi o estabelecimento de linhas bilaterais de swap entre o FED e outros bancos centrais (HELLEINER, 2014; MCDOWELL, 2012). No entanto, com o intuito de compreender a importância desta nova inovação institucional, faz-se necessário um breve comentário sobre a natureza do sistema de liquidez global sob o regime dólar-flexível. Em essência, o coração do sistema de crédito privado é o mercado de Eurodólares, que consiste fundamentalmente em depósitos em dólares realizados fora da jurisdição dos EUA e que possui atualmente um tamanho estimado em U\$20 trilhóes de dólares (GUTTMANN, 2016).

A crise de 2008 atingiu o cerne do mercado de Eurodólares ao instaurar uma profunda desconfiança entre os diversos agentes participantes que, frente à ausência de acesso às diversas camadas de proteção providas por bancos centrais, pararam de emprestar fundos uns aos outros no ápice da crise subprime. Neste sentido, pode-se visualizar o mercado de Eurodólares como um sistema de crédito privado offshore que foi originalmente desenhado para não depender dos mercados onshore "tradicionais", mas que, em decorrência da crise, acabou sem uma fonte de liquidez emergencial capaz de susten- 


\section{Gráfico 4. Denomição de Títulos da Dívida Internacionais em diferentes moedas - U\$ Bi - (2012- 2018)}

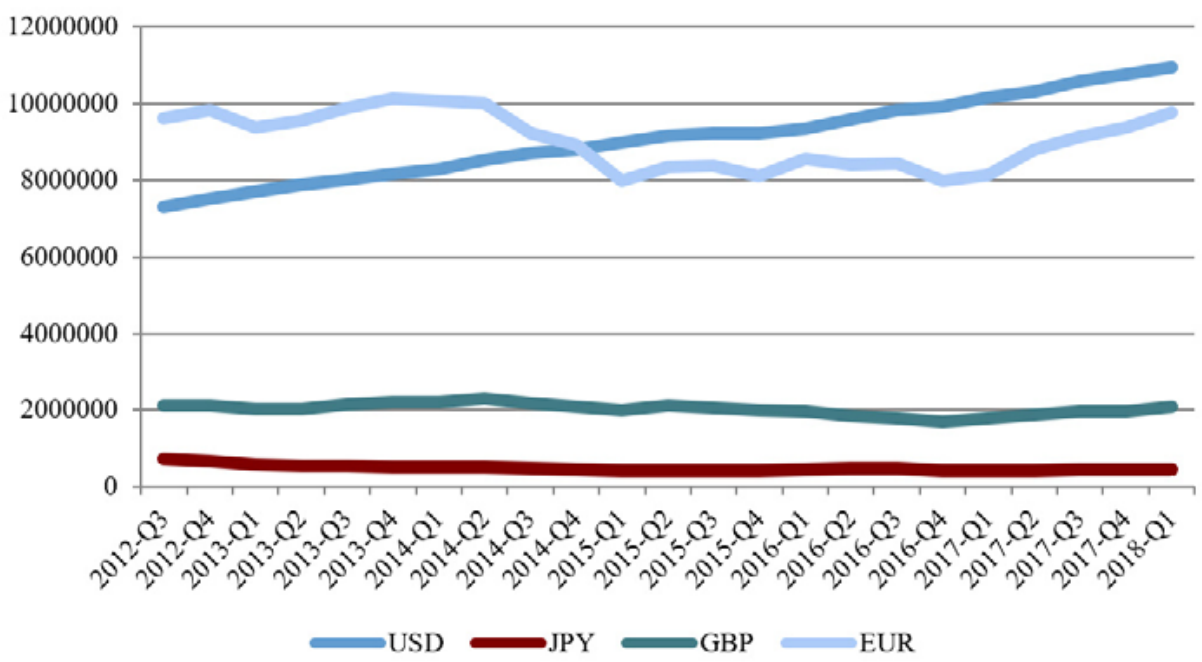

Fonte: BIS (2018)

tar este mercado em momentos de pânico (MURAU, 2018; MEHRLING, 2015).

A solução encontrada pelo FED foi estabelecer linhas de swap bilaterais com os principais bancos centrais do globo onde a criação de depósitos em dólares offshore ocorria ${ }^{13}$. As linhas de swap foram criadas entre o FED e os bancos centrais de países de alta renda como o Banco da Inglaterra, o Banco Central Europeu, o Banco Nacional Suíço, o Banco da Japão e o Banco do Canadá, além das linhas criadas com países emergentes como Coréia do Sul, Brasil, México e Cingapura, os quais permitem que os respectivos banco centrais tenham acesso a moeda um do outro utilizando como colateral uma quantidade paralela de sua moeda. Na prática, no entanto, como apontado por Murau (2018), a intenção por trás de tal iniciativa era conceder liquidez em dólar aos principais bancos centrais para que, em momentos de crise, eles pudessem emprestar para bancos na moeda estadunidense sem restriçóes, criando assim uma rede de apoio de liquidez de emergência para o mercado privado de criação de crédito de Eurodólares.

13. É relevante notar que muitas instituiçốes privada europeias tiveram acesso ao mercado interbancário dos EUA diretamente, sem precisar de auxílio de seus bancos centrais para ter acesso à dólares e sem necessitar das linhas de swap.
Do ponto de vista econômico, as linhas de swap representam uma rede de segurança para os mercados financeiros globais. No entanto, de um ponto de vista da economia política internacional, nota-se que a criação dos mesmos aprofunda o papel do FED como banco central global e o dólar como a moeda dominante do sistema monetário internacional. Ao permitir que bancos centrais disponham da liberdade de conceder liquidez em dólar em momentos de incerteza, é como se os mesmos passassem a ser braços do FED em diferentes jurisdições, solidificando assim o papel da moeda estadunidense nos mercados privados internacionais. Nos termos de Strange (1988), é possível argumentar que a criação dos swaps avançou o poder "sobre" a estrutura financeira global por parte dos EUA, o qual tornou-se capaz de controlar a liquidez e o acesso à sua moeda por outros agentes com um grau de discrição elevado, podendo assim manter o papel do dólar como moeda que está na gênese dos mercados financeiros globais.

Os argumentos e dados expostos nessa sessão apontam para a necessidade de considerar com mais profundidade o papel do sistema finan- 
ceiro na determinação de moedas internacionais. Certamente a estabilidade macroeconômica e o tamanho das redes transacionais são importantes para compreender como determinadas moedas assumem maior papel internacional. Nos mercados cambiais globais, por exemplo, o dólar ainda se mantém em $88 \%$ das transaçóes - do total de $200 \%$ - o que demonstra sua importância como moeda que desempenha o papel de meio de troca (BIS, 2018). No entanto, em uma economia global marcada pela financeirização, faz-se indispensável analisar as estruturas financeiras que concedem as diferentes moedas internacionais determinados papéis. Como visto, o dólar manteve sua importância como reserva de valor e unidade de conta, sendo o principal instrumento de endividamento mesmo após a eclosão da crise de 2008. A crescente instabilidade e necessidade de ativos líquidos e seguros também beneficiou o dólar dadas as características do mercado de títulos públicos dos EUA. Além do mais, as linhas de swap introduzem um novo elemento de controle do FED sobre a liquidez global, conferindo assim ao dólar continuidade como moeda dominante no sistema monetário internacional.

\section{Considerações finais}

A presente pesquisa demonstrou que, para compreender o papel do dólar estadunidense no período pós-2008, é fundamental dedicar atenção às características financeiras da demanda dos diversos agentes e da estrutura do sistema monetário internacional. Esta perspectiva é importante pois pode-se argumentar que o papel do dólar não é condicionado somente pela importância dos seus "fundamentais" macroeconômicos ou da competitividade dos EUA em sectores manufatureiros, mas principalmente pela sua capacidade de ser a moeda de denominação da riqueza global, através da qual parte significativa dos agentes se endivida e denomina suas operações financeiras.

Diversos autores (ex: COHEN, 2015) identificam a acumulação excessiva da dívida dos EUA como um elemento que prejudica o papel do dólar como moeda internacional. Por mais que a avaliação em torno do aumento do estoque da dívida estadunidense seja importante, é também relevante pontuar que o que guia a demanda pelo dólar é a capacidade de seu sistema financeiro, tanto onshore como offshore, de funcionar como centro global de crédito e liquidez. Portanto, nem os crescentes déficits fiscais nem o acúmulo de desequilíbrios macroeconômicos parecem ser um problema para a manutenção do padrão dólar no curto e médio prazo.

Os dados apresentados comprovam essa perspectiva. Em termos da utilização da moeda como reserva de valor no âmbito público, nota-se que a participação do dólar se manteve constante. Isto implica que a moeda continua a ser vista como safe haven por parte dos agentes econômicos e que, em momentos de incerteza, o dólar é ainda a moeda que oferece mais segurança e liquidez. Não obstante, nota-se que a moeda aumentou sua participaçáo na denominação de títulos da dívida internacionais, o que demonstra a importância do dólar nos mercados financeiros globais como instrumento de financiamento. Ou seja, a despeito da severidade da crise de 2008, não houve uma mudança significativa do modus operandi do sistema financeiro global no que tange a escolha da moeda que dá operacionalidade a arquitetura financeira internacional.

Por fim, a crise subprime demonstrou que a manutenção do padrão dólar depende em larga escala das decisões de alocação de portfolio de agentes privados e públicos. Portanto, nota-se que há uma área de pesquisa dentro das EPI relativamente pouco explorada, principalmente no que tange os determinantes da escolha de diferentes moedas nas carteiras de agentes crescentemente "financeiriza- 
dos”. Não obstante, é importante que a literatura busque responder como essa instância de decisão microeconômica se relaciona com as crescentes tensóes políticas expressas na presidência de Donald J. Trump. Conclui-se que, apesar das previsóes pessimistas em torno da manutenção do padrão dólar desde os anos 1960, não há motivos para crer que a moeda estadunidense perca sua proeminência no curto-médio prazo.

\section{Bibliografia}

BERGSTEN, C. F. The Dilemmas of the Dollar. New York: New York University Press, 1976.

BIS. Global liquidity indicators. 2018. Disponível em: $<$ https://www.bis.org/statistics/gli.htm?m=6\%7C333\%7C690>. Acesso em: 28 jul. 2018.

BOYER, R. Is a finance-led growth regime a viable alternative to fordism? A preliminary analysis. Economy \& Society, v. 29, n. 1, p. 111-145, 2000.

BUREAU OF FISCAL SERVICE. Treasury Bulletin. 2018. Disponível em: <https://www.fiscal.treasury.gov/fsreports/rpt/ treasBulletin/current.htm>. Acesso em: 28 jul. 2018.

CHINN, Menzie; FRANKEL, Jeffrey. Will the euro eventually surprass the dólar as leading international reserve currency? NBER working paper [ $\left.\mathrm{n}^{\circ} 11510\right], 2005$. Disponível em: < http://www. nber.org/papers/w11510> . Acesso em: 26 mar. 2018.

COHEN, Benjamin. Currency Power: Understanding Monetary Rivalry. Princiton: Princiton University Press, 2015.

COHEN, Benjamin. The geography of money. Ithaca: Cornell University Press, 1998.

CONTI, Bruno M. de; PRATES, Daniela M.; PLIHON, Dominique. O Sistema Monetário Internacional e seu Caráter Hierarquizado. In: CINTRA, Marcos Antônio Macedo; MARTINS, Aline Regina Alves. As transformaçóes no sistema monetário internacional. Brasília: Ipea, Cap. 1. p. 23-85. 2013

EICHENGREEN, Barry. Exorbitant Privilege: The Rise and Fall of the Dollar. Oxford: Oxford University Press, 2011.

EPSTEIN, G.A. Financialization and The World Economy. Cheltenham: Edward Elgar, 2005.

FMI. Currency Composition of Foreign Exchange Reserves. 2018. Disponível em: <http://data.imf.or$\mathrm{g} /$ ?sk=E6A5F467-C14B-4AA8-9F6D-5A09EC4E62A4\&sId $=1408243036575>$. Acesso em: 28 jul. 2018

GILPIN, Robert. War and Change in World Politics. Cambridge: Cambridge University Press, 1981.
GUTTMANN, Robert. Finance-Led Capitalism: Shadow Banking, Re-Regulation, and the Future of Global Markets. New York: Palgrave Macmillan, 2016.

HAGER, Sandy Brian. Trump and the Bond Market: Why a Flight From U.S. Treasuries Is Unlikely. In: AFFAIRS, Foreign. A New Financial Geopolitics: The U.S-Led Monetary Order in a Time of Turbulence. Washington: Foreign Affairs. p. 23-30. 2018

HELLEINER, Eric. The Status Quo Crisis: Global Financial Governance After the 2008 Meltdown. Nova Iorque: Oxford University Press, 2014.

HELLEINER, E; KIRSHNER, J. The Future of the Dollar. Ithaca, NY: Cornell University Press, 2009.

HELLEINER, Eric. Political determinants of international currencies: What future for the US dollar?. Review Of International Political Economy, [s.1.], v. 15, n. 3, p.354-378, 31 jul. 2008.

KALTENBRUNNER, Annina; LYSANDROU, Photis. The US Dollar's Continuing Hegemony as an International Currency: A Double-matrix Analysis. Development And Change, [s.l.], v. 48, n. 4, p.663-691, 8 jun. 2017.

KEOHANE, Robert O. After hegemony: Cooperation and discord in the world political economy. Princeton University Press, 2005.

KRUGMAN, Paul. The International Role of the Dollar:: Theory and Prospect. In: BILSON, John; MARSTON, Richard. Exchange Rate Theory and Practice. Chicago: Marston, p. 261-278. 1984.

MCDOWELL, Daniel. The US as 'Sovereign International Last-Resort Lender': The Fed's Currency Swap Programme during the Great Panic of 2007-09. New Political Economy, [s.l.], v. 17, n. 2, p.157-178, abr. 2012

MEHRLING, Perry. Elasticity and Discipline in the Global Swap Network. International Journal of Political Economy, v. 44, n. 4, p. 311-324, 2015.

MUNDELL, Robert. The Euro and the Stability of the International Monetary System. In: MUNDELL, Robert; CLESSE, Armand. The Euro as a Stabilizer in the International Monetary System. Nova Iorque: Springer, Cap. 5. p. 57-87. 2000

MURAU, Steffen. Offshore Dollar Creation and the Emergence of the post-2008 International Monetary System. IASS Discussion paper. Postdam, 2018.

NORRLOF, Carla. Dollar hegemony: A power analysis. Review Of International Political Economy, [s.l.], v. 21, n. 5 , p.1042-1070, 17 abr. 2014.

PRASAD, Eswar. The Dollar Trap: How the U.S dollar tightened its grip on global finance. Princeton: Princeton University Press, 2014.

PRASAD, Eswar. Gaining Currency: The Rise of the Renminbi. Oxford University Press, 2016. 
32 - Conjuntura Internacional - Belo Horizonte, ISSN 1809-6182, v.15 n.2, 22 - 32, ago. 2018

STRANGE, Susan. States and Markets. London: Continuum, 1988.

TAVARES, M.C. A retomada da hegemonia norte-americana. Revista de Economia Política, Rio de Janeiro, v. 5, n. 2, p.5-15, 1985.

TAVARES, M.C; MELIN, L.E. "Pós-escrito 1997: a reafirmação da hegemonia norte-americana”, in TAVARES, M. C. \& FIORI, J. L. (Orgs.) Poder e dinheiro: uma economia política da globalização. Rio de Janeiro: Ed. Vozes, p. 55-86, 1997.

TREASURY. MAJOR FOREIGN HOLDERS OF TREASURY SECURITIES. 2018. Disponível em: <http://ticdata. treasury.gov/Publish/mfh.txt>. Acesso em: 28 jul. 2018.

TRIFFIN, Robert. Statement of Robert Triffin to the Joint Economic Committee of the Congress. December 8th, Washington DC, Government Printing Office, 228233, 1960 . 